\title{
Original Article \\ Fermented Wheat Germ Extract (Avemar) in the Treatment of Cardiac Remodeling and Metabolic Symptoms in Rats
}

\begin{abstract}
Abishek Iyer and Lindsay Brown
School of Biomedical Sciences, The University of Queensland, Brisbane, 4072, Australia

Correspondence should be addressed to Lindsay Brown, 1.brown@uq.edu.au

Received 6 January 2009; Accepted 25 June 2009

Copyright ( 12011 A. Iyer and L. Brown. This is an open access article distributed under the Creative Commons Attribution License, which permits unrestricted use, distribution, and reproduction in any medium, provided the original work is properly cited.

Avemar, a product of industrial fermentation of wheat germ with a standardized content of benzoquinone and plant flavonoids, has been tested as an anti-cancer and immunomodulatory dietary supplement. Proposed mechanisms include anti-oxidant and anti-inflammatory actions. This study has determined whether these actions of Avemar may also be useful in the treatment of cardiovascular diseases. Two experimental rat models of cardiovascular remodeling were used in this project: the deoxycorticosterone acetate (DOCA)-salt-induced model of chronic hypertension (study I) and a high-carbohydrate/high-fat dietinduced model producing chronic symptoms of the metabolic syndrome and its associated cardiovascular complications (study II). Our results in these rat models of hypertension and diet-induced obesity show that treatment with Avemar improved cardiac function, decreased macrophage infiltration resulting in decreased collagen deposition in the ventricular myocardium, reversed an increased stiffness of the left ventricle in the diseased hearts and attenuated increased plasma malondialdehyde concentrations. In addition to the changes in the heart, Avemar reversed glucose intolerance, normalized systolic blood pressure and decreased visceral fat deposition in rats fed a high-fat/high-carbohydrate diet. In conclusion, the fermented wheat germ extract Avemar has a potential role in attenuating chronic hypertension, diabetes or metabolic syndrome-induced cardiovascular symptoms along with metabolic abnormalities such as glucose tolerance and obesity.
\end{abstract}

\section{Introduction}

Avemar is a product of industrial fermentation of wheat germ with a standardized content of benzoquinone and plant flavonoids that has been reported as safe and effective as an anti-cancer and immunomodulatory dietary supplement [1-6]. Avemar benefited patients with stage III melanoma or colorectal cancer by increasing progression-free survival $[1,3]$. Avemar supplementation reduced the incidence of treatment-related febrile neutropenia in children with solid cancers [7]. Avemar is currently being evaluated as a potential adjuvant therapeutic agent in human cancers, including those of the breast, colon, lung and prostate, with promising results as a supportive therapy with current anticancer therapies $[3,7-9]$. Preliminary results with Avemar supplementation in severe rheumatoid arthritis patients showed improved quality of life after 6 and 12 months of treatment compared with baseline measurements $[10,11]$.

Plants have provided many possible treatment options for human hypertension and metabolic diseases [12-17]. As with this wheat germ extract, the ingredients of the plant extracts responsible for the therapeutic responses are usually not known. The mechanisms which could possibly explain the responses to wheat germ extract include inhibition of poly(ADP-ribose) polymerase (PARP), decrease in MHC class I molecules, up-regulation of intercellular adhesion molecule-1 (ICAM-1), regulation of pentose phosphate pathway, inhibition of cyclooxygenase isoforms and upregulation of endogenous antioxidants $[3,6,9,18,19]$. These mechanisms may also be relevant for the treatment of cardiovascular and metabolic diseases. Decreased antioxidant concentrations resulting in oxidative stress may play an important role in the etiology of the symptoms of cardiovascular remodeling such as hypertension and hypertrophy; these antioxidant concentrations may be improved by nutraceuticals $[20,21]$. Selective cyclooxygenase and PARP inhibitors as well as antioxidant compounds have improved cardiovascular function in myocardial ischemia/reperfusion injury, heart failure, cardiomyopathies, circulatory shock, cardiovascular aging, diabetic cardiovascular complications, 
myocardial hypertrophy, atherosclerosis and vascular remodeling following injury [22-24].

Since the progression of cardiac remodeling and metabolic diseases is characterized by oxidative stress and chronic inflammation, it is possible that Avemar decreases cardiovascular remodeling, glucose intolerance and fat deposition through its reported anti-oxidant and antiinflammatory properties. Thus, we have investigated whether dietary treatment with Avemar can regulate cardiovascular remodeling and metabolic responses in hypertensive and diet-induced obese rats. Structural changes in the heart were characterized by histology and echocardiography, whereas heart function was measured in vivo using echocardiography and ex vivo in isolated perfused hearts. Isolated thoracic rings were used to measure vascular reactivity.

\section{Methods}

2.1. Male Wistar Rats. Male Wistar rats were bred at The University of Queensland Biological Resources facility. All experimental protocols were approved by the Animal Experimentation Ethics Committee of The University of Queensland, under the guidelines of the National Health and Medical Research Council of Australia. Rats were given ad libitum access to food and water and were housed in 12-h light/dark conditions. Body weight, food and water intakes were measured daily. Two experimental models of cardiovascular remodeling were used in this project: the deoxycorticosterone acetate (DOCA)-salt-induced model of chronic hypertension (study I) and a high-carbohydrate/high-fat diet-induced model producing chronic symptoms of the metabolic syndrome and its associated cardiovascular complications (study II).

All the rats in study I were uninephrectomized (UNX). Rats, 8-9 weeks old, were divided into four experimental groups of eight rats each; UNX only or treated with Avemar ( $4 \%$ mixture in powdered rat food; UNX + AVE) or UNX together with DOCA (25 mg in $0.4 \mathrm{~mL}$ dimethylformamide s.c. every fourth day) and $1 \% \mathrm{NaCl}$ in the drinking water, with or without Avemar treatment (DOCA and DOCA + AVE groups). For uninephrectomy, rats were anesthetized with an intraperitoneal injection of tiletamine $(25 \mathrm{mg} / \mathrm{kg})$ and zolazepam $(25 \mathrm{mg} / \mathrm{kg}$, Zoletil) together with xylazine ( $10 \mathrm{mg} / \mathrm{kg}$, Rompun); a lateral abdominal incision provided access to the kidney, and the left renal vessels and ureter were ligated. The left kidney was removed and weighed, and the incision site was sutured. Avemar treatment was started 4 days before surgery and continued for 28 days until the experiments were performed (treatment for 32 days).

Study II consisted of three experimental groups of 8-9 weeks old male Wistar rats treated for 16 weeks with corn starch (CS) $(n=12)$, cafeteria + beef tallow (CAF + BT) $(n=12)$ and cafeteria + beef tallow + Avemar (CAF + $\mathrm{BT}+\mathrm{AVE})(n=12)$ protocol, respectively. The CAF $+\mathrm{BT}$ diet consisted of fructose $(175 \mathrm{~g})$, powdered rat food (155 g), beef tallow (200 g), condensed milk (395 g), Hubble, Mendel and Wakeman salt mixture $(25 \mathrm{~g})$ and water $(50 \mathrm{~mL})$ per kilogram of food. The drinking water in the CAF + BT-fed rats was augmented with 25\% fructose in the water. For the control diet, fructose and condensed milk were replaced with CS (575 g) and BT was replaced with water $(200 \mathrm{~mL})$. Avemar was administered as a $4 \%$ mixture along with CAF + BT diet for 8 weeks starting 8 weeks after the initiation of the high-fat/high-carbohydrate diet (reversal protocol). Daily caloric intake was calculated from the food and water intakes using the following values $(\mathrm{kJ} / \mathrm{g})$ : fructose, 15.4; CS, 15.9; condensed milk, 13.8; BT, 37.7 and rat food, 13.5.

Systolic blood pressure was measured in study I rats after 0,2 and 4 weeks and in study II rats after 0,4 , 8,12 and 16 weeks under light sedation with i.p. injection of Zoletil (tiletamine $15 \mathrm{mg} / \mathrm{kg}$, zolazepam $15 \mathrm{mg} / \mathrm{kg}$ ). Measurements were taken using an MLT1010 Piezo-Electric Pulse Transducer (ADInstruments, Sydney, Australia) and inflatable tail-cuff connected to a MLT844 Physiological Pressure Transducer (ADInstruments) and PowerLab data acquisition unit (ADInstruments).

Fasting blood glucose concentrations were measured for study II animals with blood taken from the tail vein using Medisense Precision Q.I.D glucose meter (Abbott Laboratories, Bedford, USA). The rats were given $40 \%$ glucose solution in distilled water $(2 \mathrm{~g} / \mathrm{kg}$ body weight) via oral gavage. Tail vein blood samples were taken at $0,30,60$, 90 and 120 min following glucose administration.

Plasma malondialdehyde concentrations as a measure of oxidative stress were determined in post-mortem blood by HPLC [26].

2.2. Echocardiography. Echocardiography was performed by trained cardiac sonographers at the Small Animal Practice, School of Veterinary Sciences, The University of Queensland or The Prince Charles Hospital, Brisbane, small animal theater. Rats were anesthetized via i.p. injection with Zoletil (tiletamine $15 \mathrm{mg} / \mathrm{kg}$, zolazepam $15 \mathrm{mg} / \mathrm{kg}$ ) and Ilium Xylazil (xylazine $10 \mathrm{mg} / \mathrm{kg}$ ). Echocardiographic images of rats were obtained using the Hewlett Packard Sonos 5500 (12 MHz frequency fetal transducer) at an image depth of $3 \mathrm{~cm}$ using two focal zones. Measurements of left ventricular posterior wall thickness and internal diameter were made using twodimensional $M$-Mode taken at mid-papillary level [25].

2.3. Isolated Heart Preparation. The left ventricular function of the rats in all treatment groups was assessed using the Langendorff heart preparation. Terminal anesthesia was induced via i.p. injection of pentobarbitone sodium $100 \mathrm{mg} / \mathrm{kg}$ (Lethabarb). Once anesthesia was achieved, heparin (1000 IU) was injected into the right femoral vein. Isovolumetric ventricular function was measured by inserting a latex balloon catheter into the left ventricle connected to a Capto SP844 MLT844 physiological pressure transducer and Chart software on a Maclab system. All left ventricular enddiastolic pressure values were measured by pacing the heart at 250 beats per minute using an electrical stimulator. Enddiastolic pressures were obtained starting from $0 \mathrm{mmHg}$ up to $30 \mathrm{mmHg}$. The right and left ventricles were separated and weighed. Diastolic stiffness constant ( $\kappa$, dimensionless) was calculated as in previous studies $[26,27]$. 
TABLE 1: Physiological parameters of UNX, UNX + AVE, DOCA and DOCA + AVE-fed rats.

\begin{tabular}{|c|c|c|c|c|}
\hline Parameter & UNX (4 weeks) & UNX + AVE (4 weeks) & DOCA (4 weeks) & DOCA + AVE (4 weeks) \\
\hline Daily water intake $(\mathrm{mL})$ & $67 \pm 11(n=6)$ & $59 \pm 9(n=6)$ & $190 \pm 33^{*}(n=6)$ & $125 \pm 30^{* *}(n=6)$ \\
\hline Daily food intake (g) & $29 \pm 2(n=6)$ & $27 \pm 3(n=6)$ & $24 \pm 5(n=6)$ & $23 \pm 5(n=6)$ \\
\hline $\begin{array}{l}\text { Systolic blood pressure } \\
(\mathrm{mmHg}) 0 \text { week }\end{array}$ & $107 \pm 1.3(n=6)$ & $113 \pm 1.8(n=6)$ & $108 \pm 3.1(n=6)$ & $105 \pm 2.1(n=6)$ \\
\hline $\begin{array}{l}\text { Systolic blood pressure } \\
(\mathrm{mmHg}) 2 \text { weeks }\end{array}$ & $128 \pm 0.7(n=6)$ & $145 \pm 6^{*}(n=6)$ & $176 \pm 7.0^{*}(n=6)$ & $171 \pm 6.0^{*}(n=6)$ \\
\hline $\begin{array}{l}\text { Systolic blood pressure } \\
(\mathrm{mmHg}) 4 \text { weeks }\end{array}$ & $135 \pm 1.7(n=6)$ & $151 \pm 1.0 *(n=6)$ & $186 \pm 3.6^{*}(n=6)$ & $182 \pm 3.0 *(n=6)$ \\
\hline $\operatorname{LVIDd}(\mathrm{cm})$ & $0.66 \pm 0.01(n=6)$ & $0.57 \pm 0.01^{*}(n=6)$ & $0.48 \pm 0.02 *(n=6)$ & $0.51 \pm 0.01^{*}(n=6)$ \\
\hline LVPWd $(\mathrm{cm})$ & $0.15 \pm 0.01(n=6)$ & $0.17 \pm 0.01(n=6)$ & $0.22 \pm 0.01^{*}(n=6)$ & $0.22 \pm 0.01^{*}(n=6)$ \\
\hline Fractional shortening (\%) & $54 \pm 6(n=6)$ & $57 \pm 1.4(n=6)$ & $58 \pm 3(n=6)$ & $64 \pm 5(n=6)$ \\
\hline LV mass (g) & $0.7 \pm 0.01(n=6)$ & $0.63 \pm 0.01(n=6)$ & $0.85 \pm 0.01^{*}(n=6)$ & $0.75 \pm 0.01^{* *}(n=6)$ \\
\hline Cardiac output (mL/min) & $56 \pm 9(n=6)$ & $39 \pm 8(n=6)$ & $21 \pm 3^{*}(n=6)$ & $27 \pm 8^{*}(n=6)$ \\
\hline Ejection fraction (\%) & $87 \pm 3(n=6)$ & $92 \pm 0.7(n=6)$ & $92 \pm 2(n=6)$ & $92 \pm 1.4(n=6)$ \\
\hline Relative wall thickness & $0.49 \pm 0.01(n=6)$ & $0.94 \pm 0.2^{*}(n=6)$ & $1.49 \pm 0.68^{*}(n=6)$ & $0.94 \pm 0.2^{* *}(n=6)$ \\
\hline $\begin{array}{l}\text { LV-interstitial collagen } \\
\text { (\% of total area) }\end{array}$ & $2.7 \pm 0.3(n=5)$ & $2.4 \pm 0.5(n=5)$ & $11.7 \pm 1.3^{*}(n=6)$ & $3.8 \pm 0.7^{* *}(n=5)$ \\
\hline $\begin{array}{l}\mathrm{LV} \text { - perivascular collagen } \\
(\% \text { of total area) }\end{array}$ & $25.6 \pm 0.9(n=4)$ & $26.2 \pm 1.1(n=4)$ & $36.4 \pm 1.3^{*}(n=4)$ & $28.1 \pm 1.0^{* *}(n=4)$ \\
\hline Diastolic stiffness constant $(\kappa)$ & $20.3 \pm 0.8(n=6)$ & $19.7 \pm 1.8(n=6)$ & $32.3 \pm 1.7^{*}(n=6)$ & $22.6 \pm 0.7^{* *}(n=6)$ \\
\hline LV + septum (mg/g body wt) & $2.16 \pm 0.1(n=6)$ & $2.0 \pm 0.1(n=6)$ & $3.06 \pm 0.08^{*}(n=6)$ & $2.9 \pm 0.1^{*}(n=6)$ \\
\hline $\mathrm{RV}$ (mg/g body wt) & $0.36 \pm 0.01(n=6)$ & $0.51 \pm 0.01^{*}(n=6)$ & $0.49 \pm 0.01^{*}(n=6)$ & $0.54 \pm 0.01^{*}(n=6)$ \\
\hline Liver (mg/g body wt) & $28.2 \pm 1.7(n=6)$ & $40.6 \pm 1.4(n=6)$ & $54 \pm 2.0^{*}(n=6)$ & $45.6 \pm 3^{* *}(n=6)$ \\
\hline Spleen (mg/g body wt) & $2.4 \pm 0.17(n=6)$ & $2.4 \pm 0.1(n=6)$ & $4.3 \pm 0.2^{*}(n=6)$ & $3.1 \pm 0.1^{* *}(n=6)$ \\
\hline Remnant kidney (mg/g body wt) & $5.1 \pm 0.4(n=6)$ & $4.0 \pm 0.5(n=6)$ & $8.2 \pm 0.3^{*}(n=6)$ & $9.3 \pm 0.5^{*}(n=6)$ \\
\hline $\begin{array}{l}\text { Plasma malondialdehyde } \\
(\text { MDA) concentration }(\mu \mathrm{mol} / \mathrm{L})\end{array}$ & $19.7 \pm 0.7(n=6)$ & $20.4 \pm 0.6(n=6)$ & $27.3 \pm 0.8^{*}(n=6)$ & $23.9 \pm 0.6^{* *}(n=6)$ \\
\hline
\end{tabular}

Values are mean \pm SEM; number of experiments in parentheses. LV, left ventricle; RV, right ventricle; LVIDd, left ventricular internal diameter at diastole; LVPWd, left ventricular posterior wall thickness at diastole. LV mass calculated according to [25]. ${ }^{*} P<.05$ versus UNX; ${ }^{* *} P<.05$ versus DOCA.

2.4. Organ Bath Studies. Thoracic aortic rings $(4 \mathrm{~mm}$ in length) were suspended in an organ bath chamber with a resting tension of $10 \mathrm{mN}$. Cumulative concentrationresponse (contraction) curves were measured for noradrenaline; concentration-response (relaxation) curves were measured for acetylcholine and sodium nitroprusside in the presence of a submaximal $(70 \%)$ contraction to noradrenaline [28].

2.5. Organ Weights. Following euthanasia, the heart, liver, kidneys, visceral fat pads and spleen were removed and blotted dry for weighing. All organ weights except visceral fat pads were normalized relative to the body weight at the time of their removal (in $\mathrm{mg} / \mathrm{g}$ ). Visceral fat pads were normalized relative to tibial length at the time of removal (in $\mathrm{mg} / \mathrm{mm}$ ).

2.6. Histology. Collagen distribution was measured in the left ventricle following staining with picrosirius red and analyzed by laser confocal microscopy. Tissues were initially fixed for 3 days in Telly's fixative ( $100 \mathrm{~mL}$ of $70 \%$ ethanol, $5 \mathrm{~mL}$ of glacial acetic acid and $10 \mathrm{~mL}$ of $40 \%$ formaldehyde) and then transferred into modified Bouin's fluid $(85 \mathrm{~mL}$ of saturated picric acid, $5 \mathrm{~mL}$ glacial acetic acid and $10 \mathrm{~mL}$ of $40 \%$ formaldehyde) for 2 days. The samples were then dehydrated and embedded in paraffin wax. Thick sections $(15 \mu \mathrm{m})$ were cut and stained with image analysis under the laser scanning microscope performed as previously described $[26,29]$. Thin sections $(10 \mu \mathrm{m})$ of left ventricle were cut and stained with hematoxylin and eosin for determination of inflammatory cell infiltration.

2.7. Statistical Analysis. All data sets were represented as mean \pm SEM. Comparisons or findings between groups were made via statistical analysis of data sets using one-way/twoway analysis of variance followed by the Duncan test to determine differences between treatment groups. A $P$-value $<.05$ was considered as statistically significant.

2.8. Drugs. DOCA, heparin, noradrenaline, acetylcholine and sodium nitroprusside were purchased from Sigma Chemical Company (St Louis, MO, USA.) The fermented wheat germ extract, Avemar, was provided by Jenny Blyth, Medimpex Pty Ltd, Mudgeeraba, QLD 4213, Australia and thoroughly mixed in the food to a final concentration of $4 \%$. Noradrenaline, acetylcholine and sodium nitroprusside were dissolved in distilled water. DOCA was dissolved in 


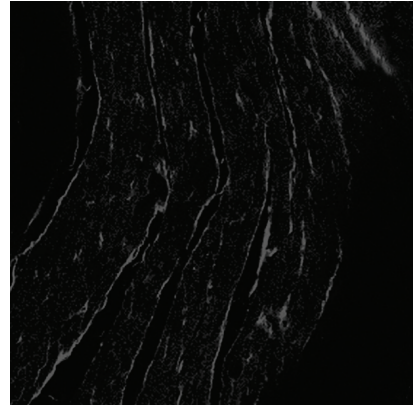

(a)

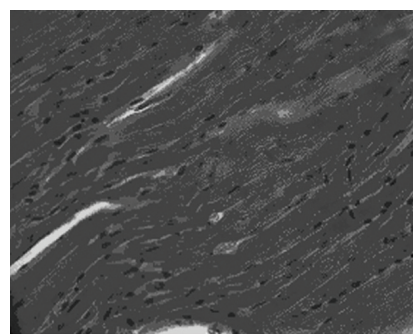

(e)

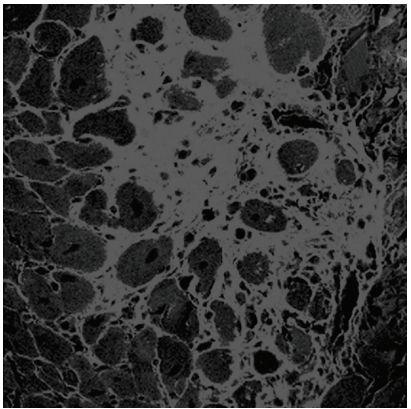

(b)

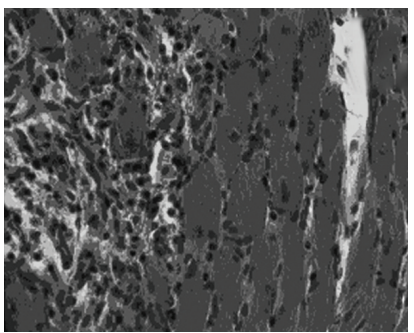

(f)

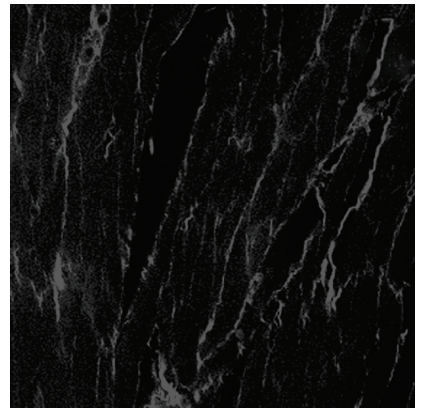

(c)

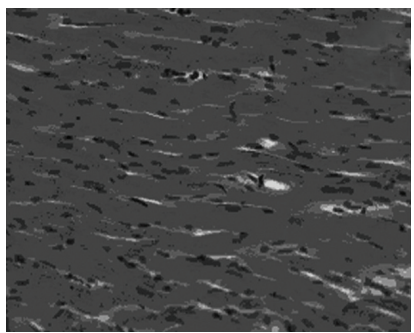

(g)

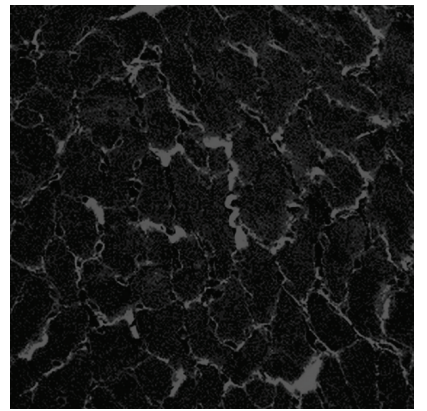

(d)

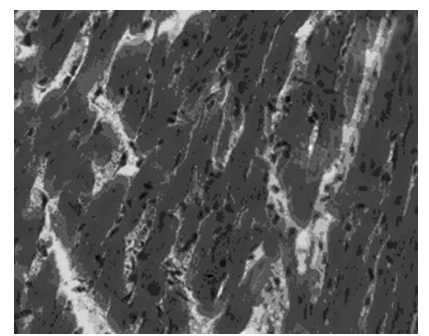

(h)

FIgURE 1: Picrosirius red staining of left ventricular interstitial collagen deposition (magnification, $\times 40)$ in UNX (a), DOCA (b), UNX + AVE (c), DOCA + AVE (d)-treated rats and hematoxylin and eosin staining of infiltrating inflammatory cells of left ventricular interstitial region (magnification, $\times 40$ ) in UNX (e), DOCA (f), UNX + AVE (g), DOCA + AVE (h)-treated rats; collagen is stained light red.

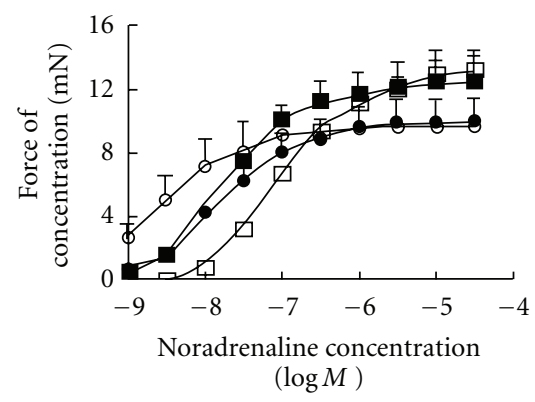

(a)

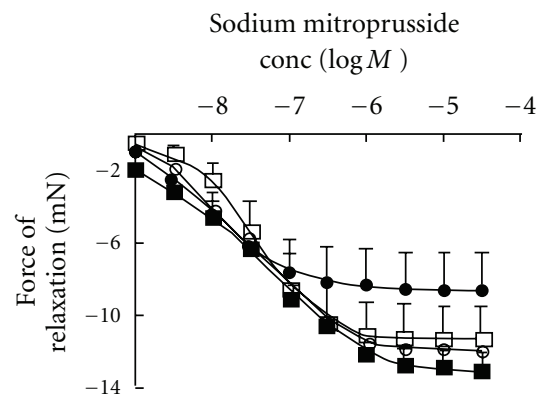

(b)

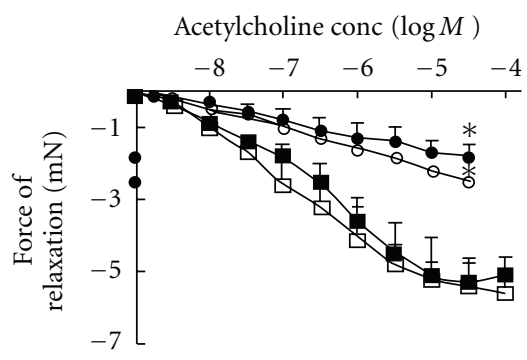

(c)

FIGURE 2: Cumulative concentration-response curves for noradrenaline (a), sodium nitroprusside (b) and acetylcholine (c) in thoracic aortic rings from UNX (filled square), UNX + AVE (open square), DOCA (filled circle) and DOCA + AVE (open circle)-fed rats after 16 weeks of feeding. ${ }^{*} P<.05$ versus UNX.

dimethylformamide with mild heating. Fructose, CS and BT were obtained through The University of Queensland Chemical Store.

\section{Results}

3.1. DOCA-Salt-Induced Rat Model of Cardiac Remodeling (Study I). Hypertension developed in DOCA-salt rats together with an increased water intake, but these rats failed to gain weight (Table 1). Avemar treatment did not change systolic blood pressure and body weight but attenuated the increased water intake (Table 1). Intake of Avemar, calculated from the daily food intake, was not significantly different between the treated groups: $2.4 \pm 0.1$ (UNX + AVE) and $2.3 \pm 0.3$ (DOCA + AVE) g/kg body wt/day, respectively. Plasma malondialdehyde concentrations, as a measure of oxidative stress, were increased in DOCA rats; this increase was attenuated by Avemar treatment (Table 1).

3.1.1. Cardiac Structure and Function. Hearts from DOCAsalt rats showed marked cardiac hypertrophy, as evidenced by increased left ventricular wet weight relative to body weight and left ventricular mass derived from echocardiography (Table 1). This was associated with a decrease in left ventricular internal diameter, indicating concentric cardiac hypertrophy (Table 1). Avemar failed to alter the decrease in left ventricular chamber diameter (Table 1). Additionally, the relative wet weights of the liver, spleen and 
the remnant kidney from DOCA-salt rats were increased (Table 1). Treatment with Avemar failed to attenuate the increased wet weights of the ventricles and the remnant kidney. Increased wet weight of both liver and spleen were attenuated with Avemar treatment (Table 1).

Echocardiographic assessment of heart function showed that Avemar attenuated the increase in relative wall thickness observed in DOCA-salt rats (Table 1). Furthermore, aortic blood flow velocities were increased and cardiac output was decreased in DOCA-salt rats; Avemar prevented the increase in blood flow velocities but failed to improve cardiac output (Table 1).

Functionally, the increased diastolic stiffness in isolated hearts from DOCA-salt rats was prevented by Avemar treatment (Table 1). Furthermore, both interstitial and perivascular collagen deposition was increased in the left ventricle of DOCA-salt rats compared to the UNX rats; this deposition was markedly attenuated by Avemar treatment (Table 1 and Figure 1) Spatial location of monocyte/macrophages determined by hematoxylin and eosin (H\&E) staining (Figure 1) showed monocyte/macrophages in the left ventricle of UNX rats in very low numbers and always as single cells. The density of monocyte/macrophages found in the left ventricle of DOCA-salt rats was significantly greater than in UNX, and these cells were usually found in clusters of cells located at scar sites and throughout the interstitium and the areas of fibrosis. Very few infiltrating cells were found in scar tissue in DOCA-salt rats treated with Avemar, predominantly due to the decreased area of scar tissue within the left ventricle; few infiltrating cells were found in the perivascular areas (Figure 1).

3.1.2. Vascular Function. In isolated thoracic aortic rings, DOCA-salt rats showed decreased contractile responses to noradrenaline (Figure 2(a)), unaltered responses to sodium nitroprusside (Figure 2(b)) together with endothelial dysfunction, defined as decreased relaxation responses to acetylcholine (Figures 2(c)). Treatment with Avemar failed to normalize these decreased responses (Figures 2(a) and 2(c)).

3.2. High-Carbohydrate/High-Fat Diet-Induced Model of Cardiac Remodeling and Metabolic Changes (Study II). Young male Wistar rats fed a high-carbohydrate/high-fat diet showed increased body weight, especially with increased abdominal fat pads, compared with CS-fed rats, without an increased food intake (Table 2). Caloric intake was similar in both diets with CS-fed rats averaging $408 \pm 38 \mathrm{~kJ} / \mathrm{day}$, whereas CAF + BT-fed rats averaged $381 \pm 47 \mathrm{~kJ} /$ day. Treatment with Avemar reversed the increase in body weight and abdominal fat pads compared to the CAF + BT-fed rats. Measurement of blood glucose concentrations after administration of a loading dose of glucose showed that CAF + BT-fed rats were glucose-intolerant as the blood glucose concentrations reduced much more slowly than in the corn starch-fed rats (Table 2). Treatment with Avemar normalized the glucose tolerance compared with CAF + BT-fed rats (Table 2).

3.2.1. Cardiac Structure and Function. Systolic blood pressure increased in CAF + BT-fed rats over the first 4 weeks

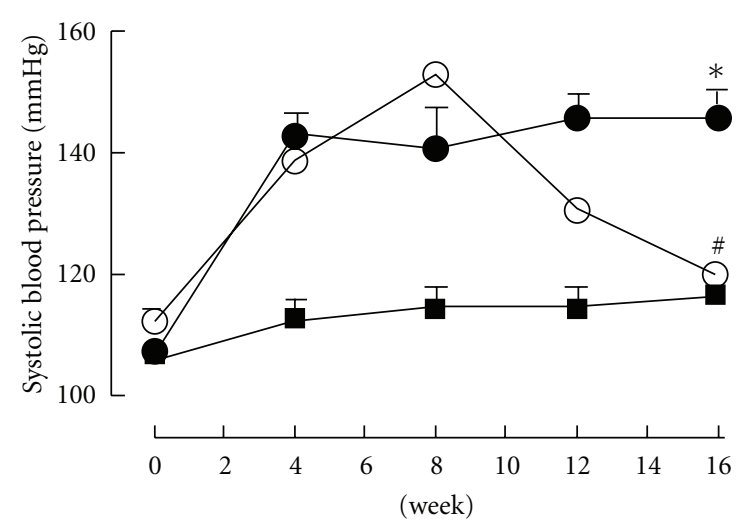

FIGURE 3: Tail-cuff measurement of systolic blood pressure recorded at $0,4,8,12$ and 16 weeks for corn starch (filled square), CAF + BT (filled circle) and $\mathrm{CAF}+\mathrm{BT}+\mathrm{AVE}$ (open circle)-fed rats. ${ }^{*} P<.05$ versus corn starch-fed rats; ${ }^{\#} P<.05$ versus $\mathrm{CAF}+\mathrm{BT}$-fed rats.

and was then maintained over the next 12 weeks with mean values of $141 \pm 6 \mathrm{mmHg}$ at 8 weeks and $146 \pm 4 \mathrm{mmHg}$ at 16 weeks. In contrast, the systolic blood pressure in corn starch-fed rats was unchanged at $115 \pm 3 \mathrm{mmHg}$ at 8 weeks and $117 \pm 4 \mathrm{mmHg}$ at 16 weeks (Figure 3). Initiating treatment with Avemar after 8 weeks of CAF + BT feeding decreased blood pressure to $131 \pm 1 \mathrm{mmHg}$ at 12 weeks and $120 \pm 2 \mathrm{mmHg}$ at 16 weeks (Figure 3). Echocardiographic assessment of CAF + BT-fed rats in vivo indicated ventricular dilatation (increased internal diameter in diastole) with increased ventricular mass and left ventricular systolic volume but with decreased contractility shown as a decreased fractional shortening and ejection fraction (Table 2). CAF + BT-fed rats showed decreased mitral valve flow rates (evaluated as a ratio of the flow rate $(\mathrm{E} / \mathrm{A})$ ) compared with the corn starch-fed rats (Table 2). Ex vivo cardiac function as measured in the Langendorff isolated heart showed a markedly increased cardiac stiffness (Table 2). These changes in cardiac structure and function were attenuated by Avemar treatment in the CAF + BT-fed rats (Table 2).

3.2.2. Organ Remodeling and Oxidative Stress. Post-mortem organ weights showed a selective increase in left ventricular wet weight and kidney weights compared with the right ventricle and other major organs in CAF + BT-fed rats compared with corn starch-fed rats (Table 2). Avemar administration reversed this organ hypertrophy in CAF + BT-fed rats. Spatial location of monocyte/macrophages determined by H\&E staining (Figure 4) shows more monocyte/macrophages in the left ventricle of the CAF+BT rats than in corn starchfed rats, and these cells were usually found in clusters of cells in the interstitial and perivascular regions of fibrosis (Table 2 and Figure 4). Furthermore, both interstitial and perivascular collagen deposition was markedly increased in the left ventricle of CAF + BT-fed rats compared to the corn starch-fed rats (Table 2 and Figure 4). Plasma malondialdehyde concentrations, as a marker of oxidative stress, were increased with $\mathrm{CAF}+\mathrm{BT}$ feeding. Avemar treatment 


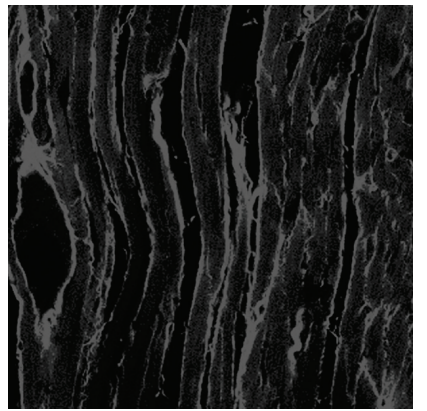

(a)

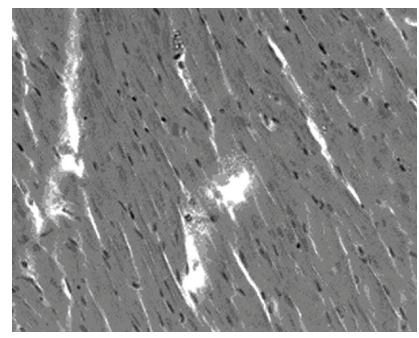

(e)

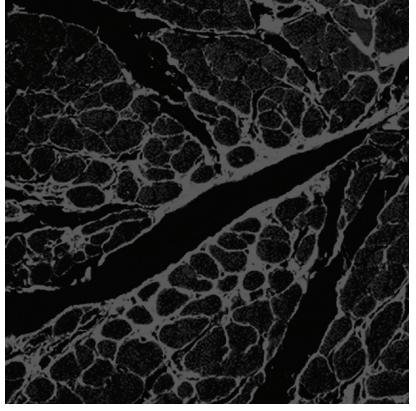

(b)

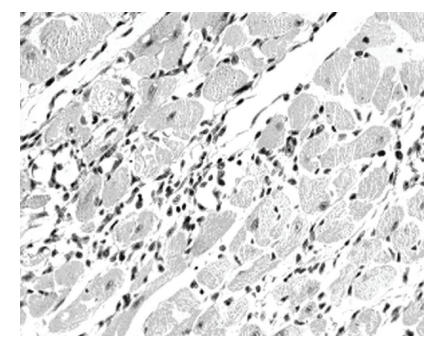

(f)

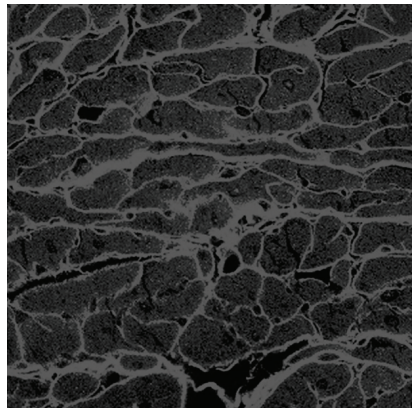

(c)

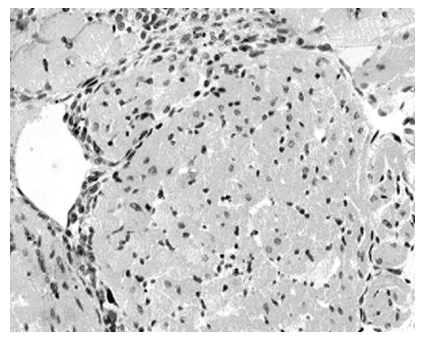

(g)

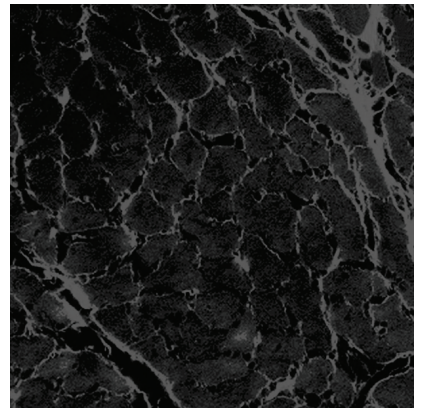

(d)

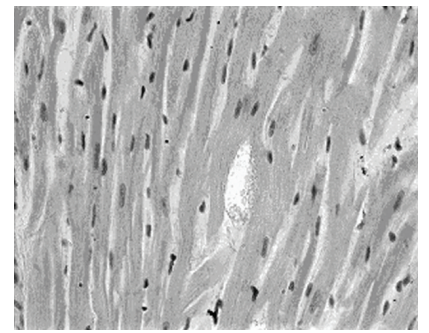

(h)

FIgURE 4: Picrosirius red staining of left ventricular interstitial collagen deposition in corn starch (16 weeks) (a), CAF + BT (8 weeks) (b), $\mathrm{CAF}+\mathrm{BT}(16$ weeks) (c) and CAF + BT + AVE (16 weeks) (d)-treated rats and hematoxylin and eosin staining of infiltrating inflammatory cells of left ventricular interstitial region (magnification, $\times 40)$ CS (16 weeks) (e), CAF + BT (8 weeks) (f), CAF + BT (16 weeks) (g) and $\mathrm{CAF}+\mathrm{BT}+\mathrm{AVE}(16$ weeks)-treated $(\mathrm{h})$ rats; collagen is stained light red.

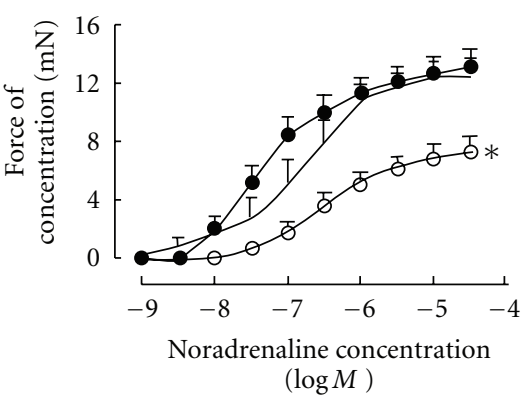

(a)

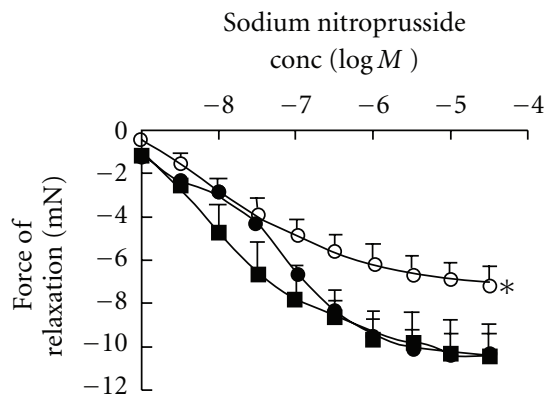

(b)

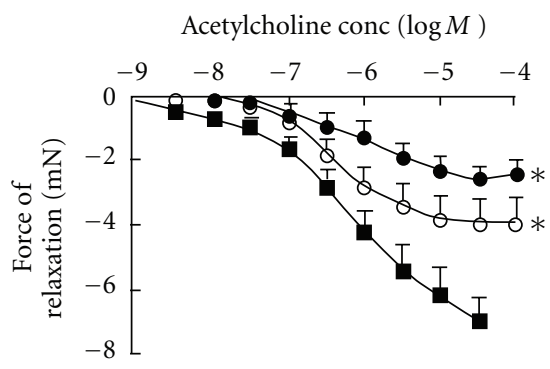

(c)

FIGURE 5: Cumulative concentration-response curves for noradrenaline (a), sodium nitroprusside (b), and acetylcholine (c) in thoracic aortic rings from corn starch (filled square), CAF + BT (filled circle) and CAF + BT + AVE (open circle)-fed rats after 16 weeks of feeding. ${ }^{*} P$ $<.05$ versus corn starch-fed rats

attenuated these increases in ventricular collagen deposition and plasma malondialdehyde concentrations (Table 2).

3.2.3. Vascular Responses. Vascular responses to noradrenaline were unchanged by CAF $+\mathrm{BT}$ feeding. Responses to sodium nitroprusside (endothelium-independent relaxation) were decreased by CAF + BT feeding (Figures 5(a) and $5(\mathrm{~b}))$. CAF $+\mathrm{BT}$ feeding induced endothelial dysfunction, shown as decreased responses to the endothelium-dependent relaxant, acetylcholine (Figure 5(c)). Treatment with Avemar failed to normalize this decreased response to acetylcholine but normalized the decreased response to sodium nitroprusside (Figures 5(b) and 5(c)). Furthermore, Avemar-treated rats showed decreased responses to noradrenaline compared with corn starch and CAF + BT-fed rats (Figure 5(a)).

\section{Discussion}

In the DOCA-salt rat model of hypertension, we have shown that treatment with Avemar improved cardiac function, decreased macrophage infiltration resulting in decreased collagen deposition in the ventricular myocardium, reversed an increased stiffness of the left ventricle in the diseased hearts and attenuated oxidative stress measured as plasma malondialdehyde concentrations without changing systolic blood pressure. Our previous studies have shown similar 
TABLE 2: Physiological parameters of CS, CAF+BT and CAF+BT+AVE-fed rats.

\begin{tabular}{|c|c|c|c|c|}
\hline Parameter & Corn starch (16 weeks) & $\mathrm{CAF}+\mathrm{BT}$ (8 weeks) & CAF + BT (16 weeks) & $\mathrm{CAF}+\mathrm{BT}+\mathrm{AVE}(16$ weeks $)$ \\
\hline Body weight (g) & $341 \pm 13(n=8)$ & $448 \pm 11(n=8)$ & $523 \pm 14(n=8)$ & $479 \pm 8(n=8)$ \\
\hline Daily water intake (mL) & $24.0 \pm 2.4(n=6)$ & $19.1 \pm 3.0(n=6)$ & $21.6 \pm 4.0(n=6)$ & $19.0 \pm 3(n=6)$ \\
\hline Daily food intake (g) & $29.0 \pm 4.3(n=6)$ & $26.1 \pm 2.8(n=6)$ & $22.4 \pm 1.8(n=6)$ & $22.0 \pm 4(n=6)$ \\
\hline Daily drug intake (g/kg/day) & N/A & N/A & $\mathrm{N} / \mathrm{A}$ & $1.83 \pm 0.25(n=6)$ \\
\hline $\begin{array}{l}\text { Fasting plasma glucose } \\
\text { concentrations }(\mathrm{mmol} / \mathrm{L})\end{array}$ & $3.2 \pm 0.5(n=6)$ & $3.5 \pm 0.1(n=6)$ & $4.0 \pm 0.1^{*}(n=6)$ & $3.6 \pm 0.1^{* *}(n=6)$ \\
\hline $\begin{array}{l}\text { Plasma glucose concentration } \\
\text { (mmol/L) (after } 120 \text { min glucose } \\
\text { loading) }\end{array}$ & $6.0 \pm 0.4(n=4)$ & $5.9 \pm 0.2(n=6)$ & $7.0 \pm 0.4^{*}(n=6)$ & $4.4 \pm 0.2^{* *}(n=6)$ \\
\hline $\operatorname{LVIDd}(\mathrm{cm})$ & $0.61 \pm 0.02(n=6)$ & $0.78 \pm 0.01^{*}(n=8)$ & $0.76 \pm 0.02 *(n=8)$ & $0.73 \pm 0.01^{*}(n=8)$ \\
\hline LVPWd (cm) & $0.18 \pm 0.01(n=4)$ & $0.16 \pm 0.01(n=8)$ & $0.20 \pm 0.01(n=8)$ & $0.17 \pm 0.01(n=8)$ \\
\hline Fractional shortening (\%) & $63 \pm 2(n=4)$ & $44 \pm 2 *(n=8)$ & $35 \pm 1^{*}(n=8)$ & $54 \pm 2^{* *}(n=8)$ \\
\hline Mitral valve flow rate (E/A) ratio & $2.1 \pm 0.1(n=6)$ & $1.8 \pm 0.1(n=6)$ & $1.1 \pm 0.01^{*}(n=6)$ & $1.4 \pm 0.12 * *(n=6)$ \\
\hline Estimated LV mass (g) & $0.82 \pm 0.06(n=4)$ & $0.88 \pm 0.03(n=8)$ & $1.01 \pm 0.05^{*}(n=8)$ & $0.82 \pm 0.03^{* *}(n=8)$ \\
\hline LV systolic volume (mL) & $0.046 \pm 0.01(n=5)$ & $0.09 \pm 0.01 *(n=8)$ & $0.127 \pm 0.01^{*}(n=8)$ & $0.040 \pm 0.01^{* *}(n=8)$ \\
\hline Cardiac output (mL/min) & $93 \pm 6(n=4)$ & $98 \pm 7(n=8)$ & $83 \pm 9(n=8)$ & $105 \pm 6(n=8)$ \\
\hline Ejection fraction $(\%)$ & $95 \pm 0.9(n=4)$ & $81 \pm 2^{*}(n=8)$ & $72 \pm 1^{*}(n=8)$ & $90 \pm 0.9^{* *}(n=8)$ \\
\hline Relative wall thickness & $0.55 \pm 0.04(n=4)$ & $0.41 \pm 0.01 *(n=8)$ & $0.51 \pm 0.04(n=8)$ & $0.45 \pm 0.01^{* *}(n=8)$ \\
\hline $\begin{array}{l}\text { LV-interstitial collagen } \\
(\% \text { of total area })\end{array}$ & $4.8 \pm 0.5(n=4)$ & $14.6 \pm 1.4^{*}(n=4)$ & $19.9 \pm 1.2^{*}(n=4)$ & $8.4 \pm 0.4^{* *}(n=4)$ \\
\hline $\begin{array}{l}\text { LV-perivascular collagen } \\
\text { (\% of total area) }\end{array}$ & $21.2 \pm 1.6(n=4)$ & $31.2 \pm 2.6^{*}(n=4)$ & $35.3 \pm 3.0^{*}(n=4)$ & $26.1 \pm 1.2^{* *}(n=4)$ \\
\hline Diastolic stiffness constant $(\kappa)$ & $20.5 \pm 0.4(n=4)$ & $26.3 \pm 2.2^{*}(n=6)$ & $27.8 \pm 1.5^{*}(n=6)$ & $21.6 \pm 1.4^{* *}(n=6)$ \\
\hline LV + septum (mg/g body wt) & $1.9 \pm 0.2(n=4)$ & $2.1 \pm 0.03(n=8)$ & $2.2 \pm 0.07(n=8)$ & $1.7 \pm 0.1^{* *}(n=8)$ \\
\hline $\mathrm{RV}$ (mg/g body wt) & $0.53 \pm 0.03(n=4)$ & $0.41 \pm 0.01^{*}(n=8)$ & $0.43 \pm 0.02 *(n=8)$ & $0.44 \pm 0.02 *(n=8)$ \\
\hline Liver (mg/g body wt) & $26.7 \pm 0.6(n=4)$ & $28.2 \pm 1.4(n=8)$ & $29.9 \pm 0.95(n=8)$ & $23.1 \pm 0.02^{* *}(n=6)$ \\
\hline Spleen (mg/g body wt) & $2 \pm 0.1(n=4)$ & $1.8 \pm 0.03(n=8)$ & $1.68 \pm 0.1(n=8)$ & $1.75 \pm 0.23(n=8)$ \\
\hline $\begin{array}{l}\text { Left and right kidney } \\
\text { (mg/g body wt) }\end{array}$ & $5.15 \pm 0.1(n=4)$ & $6.3 \pm 0.2^{*}(n=8)$ & $5.94 \pm 0.12 *(n=8)$ & $5.13 \pm 0.39^{* *}(n=8)$ \\
\hline $\begin{array}{l}\text { Abdominal fat pads } \\
\text { (mg/mm tibial length) }\end{array}$ & $401 \pm 56(n=6)$ & $343 \pm 25(n=8)$ & $826 \pm 62^{*}(n=8)$ & $339 \pm 31^{* *}(n=8)$ \\
\hline $\begin{array}{l}\text { Plasma malondialdehyde } \\
(\mathrm{MDA}) \text { concentration }(\mu \mathrm{mol} / \mathrm{L})\end{array}$ & $26.9 \pm 0.7(n=5)$ & $29.4 \pm 0.5^{*}(n=5)$ & $32.2 \pm 1.2^{*}(n=5)$ & $28.8 \pm 0.6^{* *}(n=5)$ \\
\hline
\end{tabular}

Values are mean \pm SEM; number of experiments in parentheses. LV, left ventricle; RV, right ventricle; LVIDd, left ventricular internal diameter at diastole; LVPWd, left ventricular posterior wall thickness at diastole. LV mass calculated according to [25]. ${ }^{*} P<.05$ versus CS; ${ }^{* *} P<.05$ versus CAF $+\mathrm{BT}$.

results with inhibitors of the renin-angiotensin system (captopril, candesartan and spironolactone) [27]. In contrast, we showed that treatment of DOCA-salt rats with L-arginine also decreased blood pressure in the DOCA-salt hypertensive rat [19]. In the current study, we have further shown that Avemar reversed glucose intolerance, normalized blood pressure and decreased visceral fat deposition in rats fed a high-fat/high-carbohydrate diet.

Since the mechanisms for these cardiovascular actions may be an extension of the anti-oxidant, anti-inflammatory and immunomodulatory mechanisms proposed for the anti-cancer actions of Avemar, it is worthwhile considering whether these actions improve cardiovascular function in disease models (Figure 6). Avemar produced non-specific inhibition of both cyclooxygenase isoforms, with $\mathrm{IC}_{50}$ values on COX-1 and COX-2 of $100 \mu \mathrm{g} / \mathrm{ml}$ and $300 \mu \mathrm{g} / \mathrm{ml}$, respectively [30]. In animal studies, COX inhibition decreased myocardial infarct size [24], produced scar thinning [31,32], attenuated cardiopulmonary dysfunction during endotoxemia [31, 32] and prevented angiotensin II-induced production of superoxide in cardiovascular tissue, together with the decrease in systolic blood pressure and cardiac hypertrophy in vivo [33]. Arachidonic acid metabolites are important mediators of inflammation in cardiovascular remodeling; arachidonic acid is released from membranes by phospholipase A2. Inhibition of phospholipase A2 with KH064 prevented an increase in infiltration of inflammatory cells, myocardial collagen deposition and ventricular stiffness in young spontaneously hypertensive rats [29]. Thus, the decreased collagen deposition following Avemar treatment could be mediated by these known actions as inhibitors of the production of arachidonic 


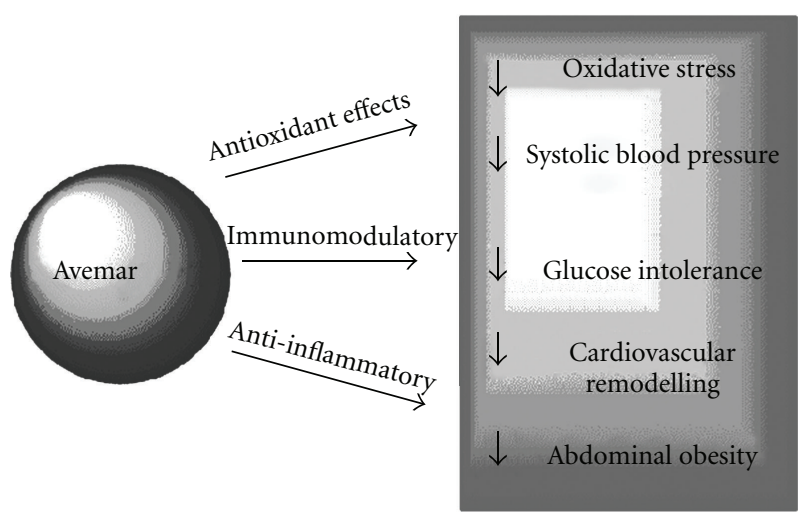

Figure 6: Potential mechanisms for the beneficial effects of Avemar in diet-induced obese rats.

acid metabolites. Further, Avemar decreased inflammation through other immunomodulatory mechanisms, such as decreased production of pro-inflammatory cytokines IL-6 and IL-10 in mice with systemic lupus erythematosus $[20,34]$ and decreased macrophage infiltration in animal models of rheumatoid arthritis [20,34]. Thus, the proposed mechanisms for the anti-cancer effects of Avemar may contribute to the cardiovascular responses in this study.

Furthermore, Avemar contains compounds such as benzoquinones and other plant flavonoids, important agents in controlling oxidative stress and cell damage [19, 34]. There is extensive literature on the therapeutic use of antioxidant compounds to improve cardiovascular function [20, 21]. Epidemiological comparisons between populations and studies within populations also support the contention that high plasma concentrations or increased dietary intake of natural antioxidant vitamins may protect against the development of cardiovascular diseases in humans [20]. Thus, an improvement in oxidative status following Avemar treatment may improve cardiovascular function.

Since inflammatory mediators are important in fat deposition [35], the anti-inflammatory mechanisms underlying the anticancer effects of Avemar may also decrease abdominal fat deposition. Furthermore, peroxisome proliferatoractivated receptor $\delta(\operatorname{PPAR} \delta)$ is of central importance in fat oxidation [35-37]. Flavonoids and phenolic acids decreased intracellular triglyceride and glucose phosphate dehydrogenase activity through down-regulating expression of adipogenic transcription factors such a PPAR $\delta$ and upregulating adiponectin expression [38]. The decrease in fat deposition and weight gain in the rats fed with a highcarbohydrate/high-fat diet with Avemar treatment could be explained by the actions of flavonoids possibly modulating adipogenic transcription factors.

Similarly, the anti-inflammatory mechanisms useful in treatment of cancer may contribute to the changes in glucose tolerance in the high-carbohydrate/high fat diet rats treated with Avemar [39, 40]. Antioxidants such as $\mathrm{N}$-acetylcysteine, vitamin $\mathrm{C}$ and $\mathrm{E}$ have also shown anti-diabetic effects possibly by protecting pancreatic $\beta$-cells from glucose toxicity, stimulating insulin secretion and moderately reducing blood glucose levels [41-43]. One of the consequences of elevated blood glucose concentrations is the non-enzymatic glycation of proteins such as hemoglobin Alc (HbAlc) and serum albumin [44]. Plant flavonoids inhibited fructose-mediated glycation of albumin improving the symptoms of diabetes [44].

Other components of Avemar such as the benzoquinones may also be cardioprotective. Benzoquinones have very similar characteristics to vitamins and are anti-oxidant compounds. Coenzyme Q10 (ubiquinone) is a naturally occurring benzoquinone, which may prevent cellular damage during myocardial ischemia and reperfusion by its roles in oxidative phosphorylation and membrane stabilization [45]; diabetes induced a decrease in coenzyme Q plasma levels [46]. Coenzyme Q10 and alpha-tocopherol treatment decreased glycated $\mathrm{HbAlc}$ and pancreatic lipid peroxidation in diabetic rats [40]. Coenzyme Q10 has also been used in oral form to treat various cardiovascular disorders including angina pectoris, hypertension and congestive heart failure $[45,47]$.

In conclusion, our results show that the fermented wheat germ extract Avemar has a potential role to attenuate the cardiovascular symptoms induced by hypertension, diabetes or the metabolic syndrome while moderating metabolic abnormalities such as glucose tolerance and obesity. Since Avemar is already available in humans as a complementary therapy for cancer, this product could be further evaluated in a clinical setting as an adjunct therapy for preventing cardiovascular and metabolic symptoms.

\section{Funding}

The University of Queensland; Medimpex Pty Ltd, Mudgeeraba, Australia.

\section{References}

[1] M. Hidvégi, E. Rásó, R. Tömösközi-Farkas et al., "MSC, a new benzoquinone-containing natural product with antimetastatic effect," Cancer Biotherapy and Radiopharmaceuticals, vol. 14, no. 4, pp. 277-289, 1999.

[2] M. Hidvégi, E. Ráso, R. Tömösközi-Farkas, S. Paku, K. Lapis, and B. Szende, "Effect of Avemar and Avemar + vitamin C on tumor growth and metastasis in experimental animals," Anticancer Research, vol. 18, no. 4A, pp. 2353-2358, 1998.

[3] L. V. Demidov, L. V. Manziuk, G. Y. Kharkevitch, N. A. Pirogova, and E. V. Artamonova, "Adjuvant fermented wheat germ extract (Avemar ${ }^{\mathrm{TM}}$ ) nutraceutical improves survival of high-risk skin melanoma patients: a randomized, pilot, phase II clinical study with a 7-year follow-up," Cancer Biotherapy and Radiopharmaceuticals, vol. 23, no. 4, pp. 477-482, 2008.

[4] Egészségügyi Tudományos Tanács Elnöksége, "Recommendation of the Health Sciences Council's Presidency regarding the legal prerequisites for the legal use of AVEMAR dietary supplement as a neoplastic agent," Orvosi Hetilap, vol. 148, p. 173, 2007.

[5] M. Hidvégi, E. Rásó, R. T. Farkas, K. Lapis, and B. Szende, "Effect of MSC on the immune response of mice," Immunopharmacology, vol. 41, no. 3, pp. 183-186, 1999. 
[6] J. T. Heimbach, G. Sebestyen, G. Semjen, and E. Kennepohl, "Safety studies regarding a standardized extract of fermented wheat germ," International Journal of Toxicology, vol. 26, no. 3, pp. 253-259, 2007.

[7] M. Garami, D. Schuler, M. Babosa et al., "Fermented wheat germ extract reduces chemotherapy-induced febrile neutropenia in pediatric cancer patients," Journal of Pediatric Hematology/Oncology, vol. 26, no. 10, pp. 631-635, 2004.

[8] F. Jakab, Y. Shoenfeld, Á. Balogh et al., "A medical nutriment has supportive value in the treatment of colorectal cancer," British Journal of Cancer, vol. 89, no. 3, pp. 465-469, 2003.

[9] M. Nichelatti and M. Hidvégi, "Experimental and clinical results with Avemar (a dried extract from fermented wheat germ) in animal cancer models and in cancer patients," Nógyógyászati Onkológia, vol. 7, pp. 180-185, 2002.

[10] A. Telekes, A. Resetar, G. Balint et al., "Fermented wheat germ extract (Avemar) inhibits adjuvant arthritis," Annals of the New York Academy of Sciences, vol. 1110, pp. 348-361, 2007.

[11] G. Bálint, Á. Apáthy, M. Gaál et al., "Effect of Avemar®_a fermented wheat germ extract—on rheumatoid arthritis. Preliminary data," Clinical and Experimental Rheumatology, vol. 24, no. 3, pp. 325-328, 2006.

[12] V. S. Retelny, A. Neuendorf, and J. L. Roth, "Nutrition protocols for the prevention of cardiovascular disease," Nutrition in Clinical Practice, vol. 23, no. 5, pp. 468-476, 2008.

[13] J. H. O'Keefe, N. M. Gheewala, and J. O. O'Keefe, "Dietary strategies for improving post-prandial glucose, lipids, inflammation, and cardiovascular health," Journal of the American College of Cardiology, vol. 51, no. 3, pp. 249-255, 2008.

[14] M. C. Houston, B. Cooil, B. J. Olafsson, and P. Raggi, "Juice powder concentrate and systemic blood pressure, progression of coronary artery calcium and antioxidant status in hypertensive subjects: a pilot study," Evidence-Based Complementary and Alternative Medicine, vol. 4, pp. 455-462, 2007.

[15] S. Samane, J. Noël, Z. Charrouf, H. Amarouch, and P. S. Haddad, "Insulin-sensitizing and anti-proliferative effects of Argania spinosa seed extracts," Evidence-Based Complementary and Alternative Medicine, vol. 3, no. 3, pp. 317-327, 2006.

[16] I. S. R. Punitha, K. Rajendran, A. Shirwaikar, and A. Shirwaikar, "Alcoholic stem extract of Coscinium fenestratum regulates carbohydrate metabolism and improves antioxidant status in streptozotocin-nicotinamide induced diabetic rats," Evidence-Based Complementary and Alternative Medicine, vol. 2, no. 3, pp. 375-381, 2005.

[17] B. Qin, M. Nagasaki, M. Ren, G. Bajotto, Y. Oshida, and Y. Sato, "Gosha-jinki-gan (a herbal complex) corrects abnormal insulin signaling," Evidence-Based Complementary and Alternative Medicine, vol. 1, pp. 269-276, 2004.

[18] G. L. Johanning and F. Wang-Johanning, "Efficacy of a medical nutriment in the treatment of cancer," Alternative Therapies in Health and Medicine, vol. 13, no. 2, pp. 56-63, 2007.

[19] L. G. Boros, M. Nichelatti, and Y. Shoenfeld, "Fermented wheat germ extract (Avemar) in the treatment of cancer and autoimmune diseases," Annals of the New York Academy of Sciences, vol. 1051, pp. 529-542, 2005.

[20] M. C. Houston, "Nutraceuticals, vitamins, antioxidants, and minerals in the prevention and treatment of hypertension," Progress in Cardiovascular Diseases, vol. 47, no. 6, pp. 396-449, 2005.

[21] C. A. Hamilton, W. H. Miller, S. Al-Benna et al., "Strategies to reduce oxidative stress in cardiovascular disease," Clinical Science, vol. 106, no. 3, pp. 219-234, 2004.
[22] P. Pacher and C. Szabó, "Role of poly(ADP-ribose) polymerase 1 (PARP-1) in cardiovascular diseases: the therapeutic potential of PARP inhibitors," Cardiovascular Drug Reviews, vol. 25, no. 3, pp. 235-260, 2007.

[23] R. Wu, M.-A. Laplante, and J. de Champlain, "Cyclooxygenase-2 inhibitors attenuate angiotensin IIinduced oxidative stress, hypertension, and cardiac hypertrophy in rats," Hypertension, vol. 45, no. 6, pp. 1139-1144, 2005.

[24] E. R. Gross, A. K. Hsu, and G. J. Gross, "Acute aspirin treatment abolishes, whereas acute ibuprofen treatment enhances morphine-induced cardioprotection: role of 12-lipoxygenase," Journal of Pharmacology and Experimental Therapeutics, vol. 310, no. 1, pp. 185-191, 2004.

[25] L. Brown, A. Fenning, V. Chan et al., "Echocardiographic assessment of cardiac structure and function in rats," Heart Lung and Circulation, vol. 11, no. 3, pp. 167-173, 2002.

[26] A. Fenning, G. Harrison, R. Rose'meyer, A. Hoey, and L. Brown, "L-Arginine attenuates cardiovascular impairment in DOCA-salt hypertensive rats," American Journal of Physiology, vol. 289, no. 4, pp. H1408-H1416, 2005.

[27] L. Brown, B. Duce, G. Miric, and C. Sernia, "Reversal of cardiac fibrosis in deoxycorticosterone acetate-salt hypertensive rats by inhibition of the renin-angiotensin system," Journal of the American Society of Nephrology, vol. 10, no. 1, pp. S143S148, 1999.

[28] L. Brown, E. J. Cragoe Jr., K. C. Abel, S. W. Manley, and J. R. Bourke, "Amiloride analogues induce responses in isolated rat cardiovascular tissues by inhibition of $\mathrm{Na}^{+} / \mathrm{Ca} 2^{+}$exchange," Naunyn-Schmiedeberg's Archives of Pharmacology, vol. 344, no. 2, pp. 220-224, 1991.

[29] S. Levick, D. Loch, B. Rolfe et al., "Antifibrotic activity of an inhibitor of group IIA secretory phospholipase A2 in young spontaneously hypertensive rats," Journal of Immunology, vol. 176, no. 11, pp. 7000-7007, 2006.

[30] C. Illmer, S. Madlener, Z. Horvath et al., "Immunologic and biochemical effects of the fermented wheat germ extract avemar," Experimental Biology and Medicine, vol. 230, no. 2, pp. 144-149, 2005.

[31] S. M. Heidemann, J. P. Ofenstein, and A. P. Sarnaik, "Ibuprofen attenuates cardiopulmonary dysfunction by modifying vascular tone in endotoxemia," Prostaglandins Leukotrienes and Essential Fatty Acids, vol. 60, no. 3, pp. 181-185, 1999.

[32] E. J. Brown Jr., R. A. Kloner, and F. J. Schoen, "Scar thinning due to ibuprofen administration after experimental myocardial infarction," American Journal of Cardiology, vol. 51, no. 5, pp. 877-883, 1983.

[33] R. Wu, M.-A. Laplante, and J. de Champlain, "Prevention of angiotensin II-induced hypertension, cardiovascular hypertrophy and oxidative stress by acetylsalicylic acid in rats," Journal of Hypertension, vol. 22, no. 4, pp. 793-801, 2004.

[34] S. G. Sukkar and E. Rossi, "Oxidative stress and nutritional prevention in autoimmune rheumatic diseases," Autoimmunity Reviews, vol. 3, no. 3, pp. 199-206, 2004.

[35] L. F. Van Gaal, I. L. Mertens, and C. E. de Block, "Mechanisms linking obesity with cardiovascular disease," Nature, vol. 444, no. 7121, pp. 875-880, 2006.

[36] M. A. Jay and J. Ren, "Peroxisome proliferator-activated receptor (PPAR) in metabolic syndrome and type 2 diabetes mellitus," Current Diabetes Reviews, vol. 3, no. 1, pp. 33-39, 2007. 
[37] R. Dumasia, K. A. Eagle, E. Kline-Rogers, N. May, L. Cho, and D. Mukherjee, "Role of PPAR- gamma agonist thiazolidinediones in treatment of pre-diabetic and diabetic individuals: a cardiovascular perspective," Current Drug Targets: Cardiovascular \& Haematological Disorders, vol. 5, pp. 377-386, 2005.

[38] C.-L. Hsu and G.-C. Yen, "Effects of capsaicin on induction of apoptosis and inhibition of adipogenesis in 3T3-L1 cells," Journal of Agricultural and Food Chemistry, vol. 55, no. 5, pp. 1730-1736, 2007.

[39] P. Dandona, A. Aljada, A. Chaudhuri, P. Mohanty, and R. Garg, "A novel view of metabolic syndrome," Metabolic Syndrome and Related Disorders, vol. 2, no. 1, pp. 2-8, 2004.

[40] P. Dandona, A. Chaudhuri, H. Ghanim, and P. Mohanty, "Anti-inflammatory effects of insulin and the proinflammatory effects of glucose," Seminars in Thoracic and Cardiovascular Surgery, vol. 18, no. 4, pp. 293-301, 2006.

[41] H. Kaneto, Y. Kajimoto, J. Miyagawa et al., "Beneficial effects of antioxidants in diabetes: possible protection of pancreatic $\beta$-cells against glucose toxicity," Diabetes, vol. 48, no. 12, pp. 2398-2406, 1999.

[42] L. Franzini, D. Ardigò, and I. Zavaroni, "Dietary antioxidants and glucose metabolism," Current Opinion in Clinical Nutrition and Metabolic Care, vol. 11, no. 4, pp. 471-476, 2008.

[43] Y. Minamiyama, S. Takemura, T. Tsukioka et al., "Effect of $\mathrm{AOB}$, a fermented-grain food supplement, on oxidative stress in type 2 diabetic rats," BioFactors, vol. 30, no. 2, pp. 91-104, 2007.

[44] R. P. Dearlove, P. Greenspan, D. K. Hartle, R. B. Swanson, and J. L. Hargrove, "Inhibition of protein glycation by extracts of culinary herbs and spices," Journal of Medicinal Food, vol. 11, no. 2, pp. 275-281, 2008.

[45] S. Greenberg and W. H. Frishman, "Co-enzyme Q10: a new drug for cardiovascular disease," Journal of Clinical Pharmacology, vol. 30, no. 7, pp. 596-608, 1990.

[46] C. M. Sena, E. Nunes, A. Gomes et al., "Supplementation of coenzyme Q10 and $\alpha$-tocopherol lowers glycated hemoglobin level and lipid peroxidation in pancreas of diabetic rats," Nutrition Research, vol. 28, no. 2, pp. 113-121, 2008.

[47] S. Pepe, S. F. Marasco, S. J. Haas, F. L. Sheeran, H. Krum, and F. L. Rosenfeldt, "Coenzyme Q10 in cardiovascular disease," Mitochondrion, vol. 7, pp. S154-S167, 2007. 


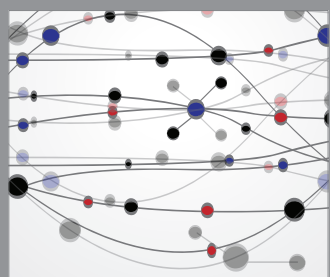

The Scientific World Journal
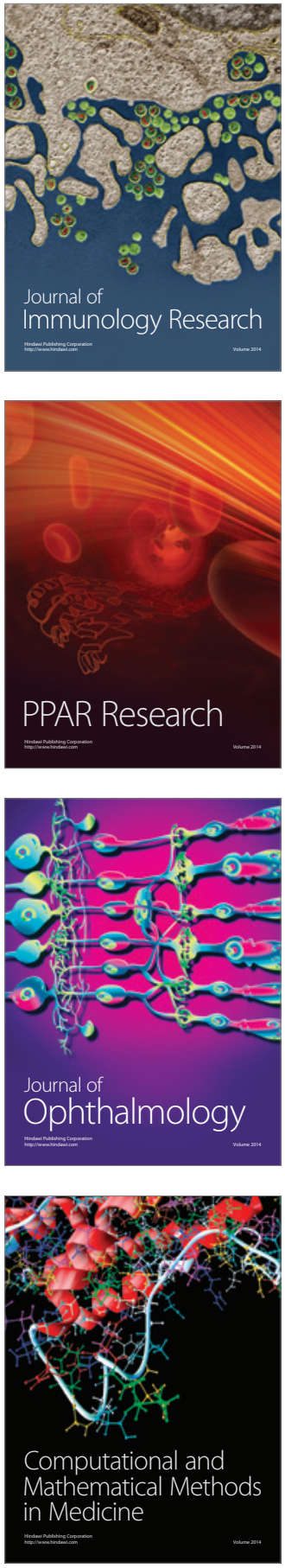

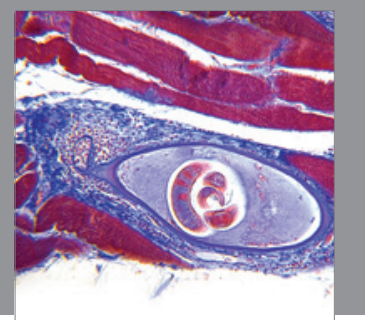

Gastroenterology

Research and Practice
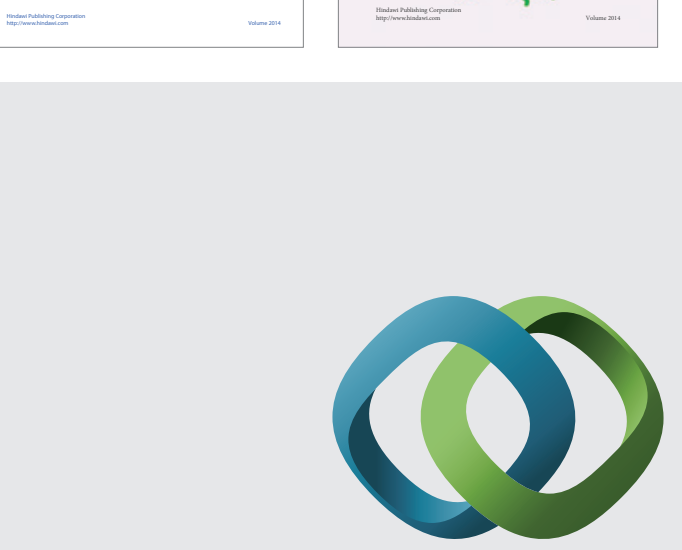

\section{Hindawi}

Submit your manuscripts at

http://www.hindawi.com
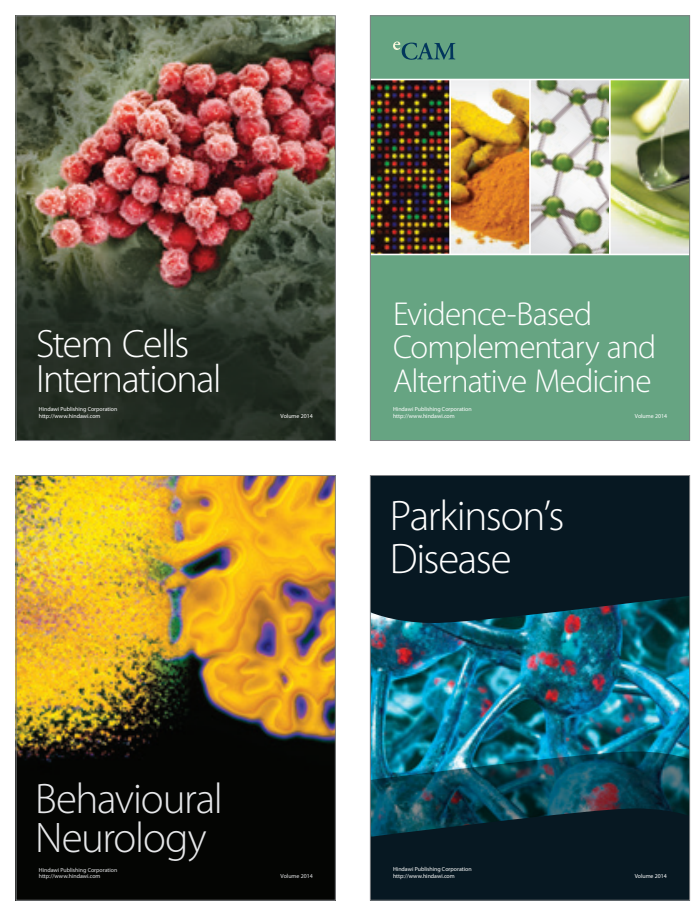

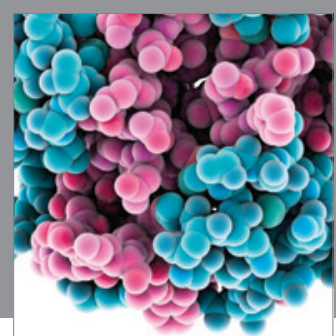

Journal of
Diabetes Research

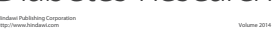

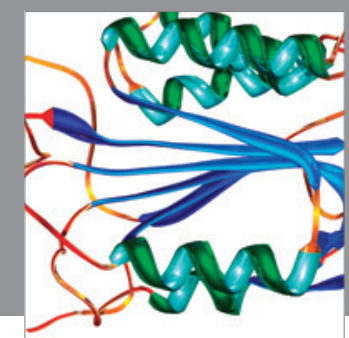

Disease Markers
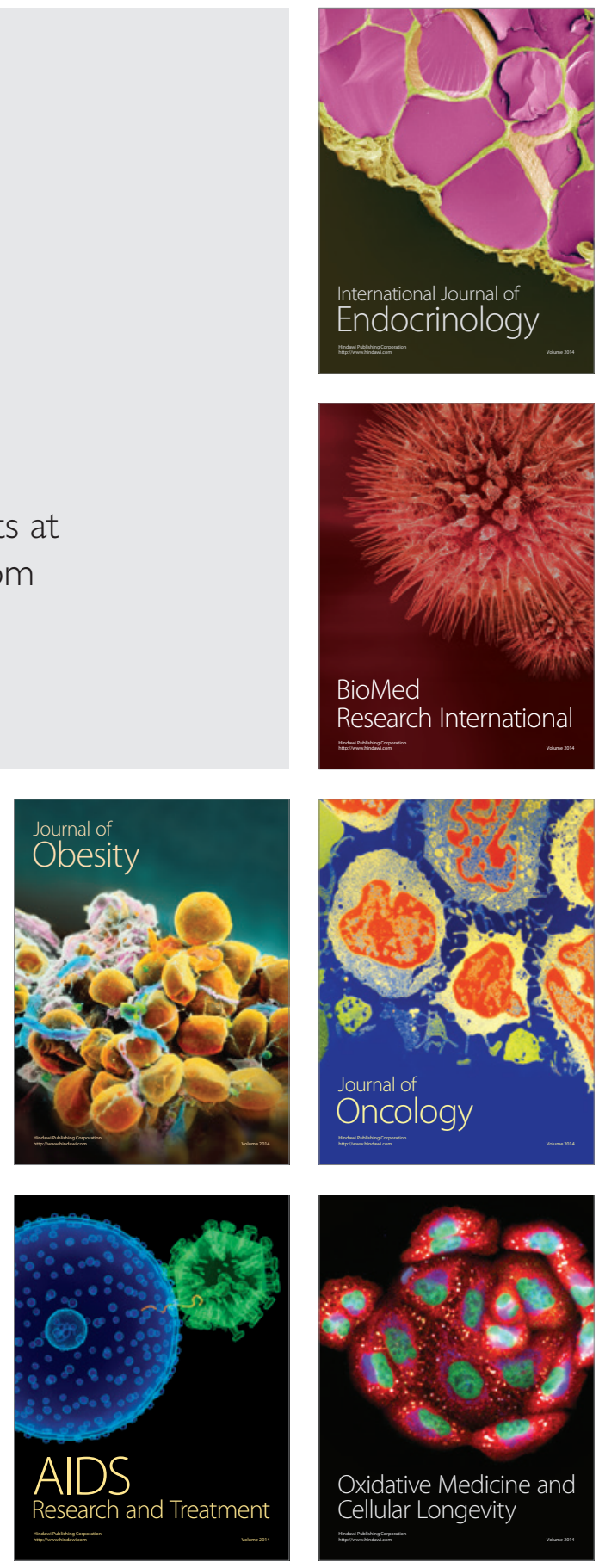